\title{
LIFE AVERAGE DAILY DOSE OF RADIUM-226 ON SOME WATER SAMPLES COLLECTED AT GIRI AND KUJE AREA OF ABUJA, NORTH-CENTRAL NIGERIA
}

\author{
OMEJE MAXWELL ${ }^{1}$, JOEL EMMANUEL SUNDAY ${ }^{1}$, ADEWOYIN OLUSEGUN OLADOTUN ${ }^{1}$, \\ AKINWUMI SAYO AKINLOYE ${ }^{1}$, PRAISEGOD CHIDOZIE EMENIKE ${ }^{1}$, \\ IMOKHAI THEOPHILUS TENEBE ${ }^{1}$, OLATOKUNBO OFUYATAN ${ }^{1}$, \\ OKOLIE TOBIAS SOCIIS ${ }^{1} \&$ HUSIN WAGIRAN $^{2}$ \\ ${ }^{1}$ Covenant University, Nigeria \\ ${ }^{2}$ Universiti Teknologi Malaysia, Malaysia
}

\begin{abstract}
${ }^{226} \mathrm{Ra}$ concentrations were studied to represent the radiological risk of groundwater of the Giri and Kuje areas of Abuja, North-Central Nigeria. Two borehole water samples were collected from the Giri and Kuje areas of Abuja with a hand-dug well and Abuja Water Board as control. Inductively Coupled Plasma Mass Spectrometry (ICP-MS) was used to measure the concentrations of radionuclide of ${ }^{226} \mathrm{Ra}$ exposed to the dwellers. The activity concentrations of ${ }^{226} \mathrm{R}$ in groundwater supplies for drinking and domestic purposes ranges from $443 \mu \mathrm{Bq} \mathrm{L} \mathrm{L}^{-q}$ to $849 \mu \mathrm{Bq} \mathrm{L} \mathrm{L}^{-1}$, with the highest value of $849 \mu \mathrm{Bq} \mathrm{L} \mathrm{L}^{-1}$ found at the Kuje borehole; the lowest value of $443 \mu \mathrm{Bq} \mathrm{L} \mathrm{L}^{-\mathrm{q}}$ was reported at the Giri borehole. This higher activity value found at the Kuje borehole may be attributed to a basaltic dyke intrusion that outcrops in the region which is used for a quarry. The concentration was used to calculate the Life Average Daily Dose of ${ }^{226} \mathrm{Ra}$ individuals collected in the area, which was estimated to be $5.0 \times$ $10^{-3} \mu \mathrm{g} \mathrm{kg}{ }^{-\mathrm{k}}$ day $^{-\mathrm{d}}$ and was found to be lower than the International Reference Level. This present study recommends further research on ${ }^{226} \mathrm{Ra}$ levels and exposure to inhabitants via groundwater for a comprehensive conclusion to be drawn for future toxicity and toxicological health-related diseases.

Keywords: ICP-MS, radionuclide, radium-226, Abuja, groundwater.
\end{abstract}

\section{INTRODUCTION}

Four natural isotopes can be obtained from radium $\left({ }^{223} \mathrm{Ra},{ }^{224} \mathrm{Ra},{ }^{226} \mathrm{Ra}\right.$, and ${ }^{228} \mathrm{Ra},{ }^{226} \mathrm{Ra}$ and ${ }^{228} \mathrm{Ra}$ ) which are moderately soluble in water [1]. The penetration of radium to subsurface ground water systems occurs through desorption from sediments, the dissolution of aquifers bearing rocks and ejection processes of minerals from decay series of radioactive materials in the bedrock [1]. However, the concentration of radium in groundwater depends on the activity concentration of radium in the bedrock as well as promotional mechanisms such as complexations, precipitation - dissolution and adsorption - desorption which influences the transport of radium in water. These processes contribute to the chemical constituents of groundwater [2]. The toxicity of the human kidney by chronic ingestion of the uranium through drinking water ranges from 0.004 to $9 \mu \mathrm{g} \mathrm{L^{-1 }}$ per body weight per day and may produce interference with kidney function [3]. In more recent studies on humans by Kurttio et al. [3], nephrotoxic complications could result from the presence of uranium in drinking water without clear threshold. A previous study also revealed that the ingestion of radium was causally associated with leukaemia in humans [4]. Other epidemiological research itemized heightened risks of osteosarcoma and radium in potable water [5], [6]. Considering the high radiotoxicity of ${ }^{226} \mathrm{Ra}$ and ${ }^{228} \mathrm{Ra}$, their presence in water and the associated health risks require particular attention. This present study aims to estimate the toxicity risk of ${ }^{266} \mathrm{Ra}$ in water samples made for drinking. The study locations are Kuje (lat. 8 ${ }^{\circ} 56^{\prime} 16.7^{\prime \prime} \mathrm{N}$ and long. 7¹1’46.0”E) and Giri (lat. 856’45.6”N and long. 7013’26.2”E). 


\section{GEOLOGY OF THE STUDY AREA}

The study area is located within the crystalline basement of Nigeria. The dominant rock units in the area comprise mainly of migmatitic and granitic gneisses, granites, granodiorites and amphibolites. The study area is in the basement complex with undifferentiated migmatite complex of Proterozoic to Archean origin, metavolcano-Sedimentary rocks of Late Proterozoic age and Older Granite Complex of Late Precambrian - Lower Paleozoic age, also known as Pan-African Granites. The rocks are generally weathered into reddish micaceous sandy clay to clay materials, capped by laterite. Detailed reports of the hydrological description, age, history, structure and geochemistry of the Basement Complex of Nigeria are given in Oyawoye [7], Black et al. [8] and Rahaman [9]. The study locations are Kuje (lat. $8^{\circ} 56^{\prime} 16.7^{\prime \prime} \mathrm{N}$ and long. $7^{\circ} 11^{\prime} 46.0^{\prime \prime} \mathrm{E}$ ) and Giri (lat. $8^{\circ} 56^{\prime} 45.6^{\prime \prime} \mathrm{N}$ and long. $\left.7^{\circ} 13^{\prime} 26.2^{\prime \prime} \mathrm{E}\right)$. The geologic map of boreholes drilled for this study areas are shown in Fig. 1.

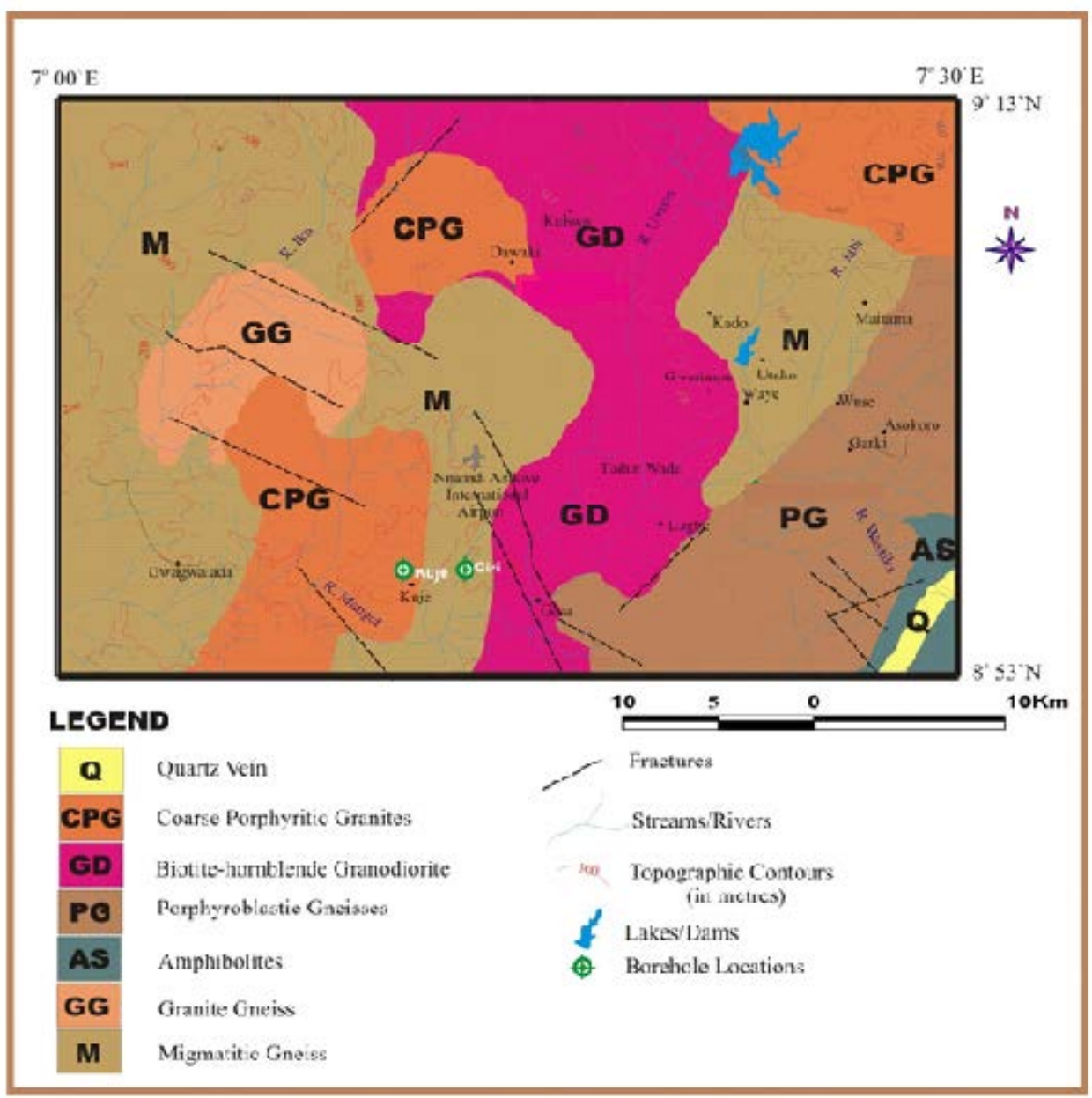

Figure 1: Geologic map of the study area showing the borehole points. 


\section{SAMPLING AND SAMPLE COLLECTION}

Two different boreholes of varying depth were drilled with the help of a rig machine of 25 torn capacity and attached with a compressor of 30 torn capacity so as to drive the drilling pipes to a recommended depth of about $60 \mathrm{~m}$ and $50 \mathrm{~m}$, respectively, for the Kuje and Giri areas of Abuja. A hand-dug well with a shallow depth of about $14 \mathrm{~m}$ and Water Board (public water supply) in Abuja and suburbs were collected for comparison. The samples were collected in high-density polyethylene containers at the site and washed with a solution of $10 \%$ nitric acid for 15 minutes, followed by repeated rinsing with distilled water and finally a rinse with ultrapure water (resistivity of about $18 \mathrm{Mnsin}^{-1}$ ). The water samples were stabilized with $5 \mathrm{ml}$ of nitric acid in each litre of water in order to prevent it from adsorbing the wall of the container. Fig. 2(a) and (b) shows the lithologies for boreholes where the water samples were collected for the present study.

\section{DETERMINATION OF ${ }^{226}$ RA IN WATER SAMPLES USING ICP-MS}

Six water samples were taken according to the standard procedure [1], [11]. The water samples in plastic pellets were acidified to $0.1 \mathrm{M} \mathrm{HCL}$ and the addition of ${ }^{228} \mathrm{Th}$ tracer in the presence of ion exchange separator. $10 \mathrm{~mL} 8 \mathrm{M} \mathrm{HNO}$ was added in a solution of hydrogenated titanium oxide (HTiO HTiO). The HTiO was used as a co-precipitation which was diluted with $12 \mathrm{~mL} 1 \mathrm{M}$ HCL into a micro-coprecipitation of $\mathrm{BaSO}_{4}$ [7]-[9]. The determination of ${ }^{226} \mathrm{Ra}$ was carried out according to Oyawoye [7] and Dai et al. [10]. The MDA of the system is approximately $0.22 \mathrm{BqL}^{-1}$ with 4 hours counting and $0.09 \mathrm{BqL}^{-1}$ with 20 hours counting.

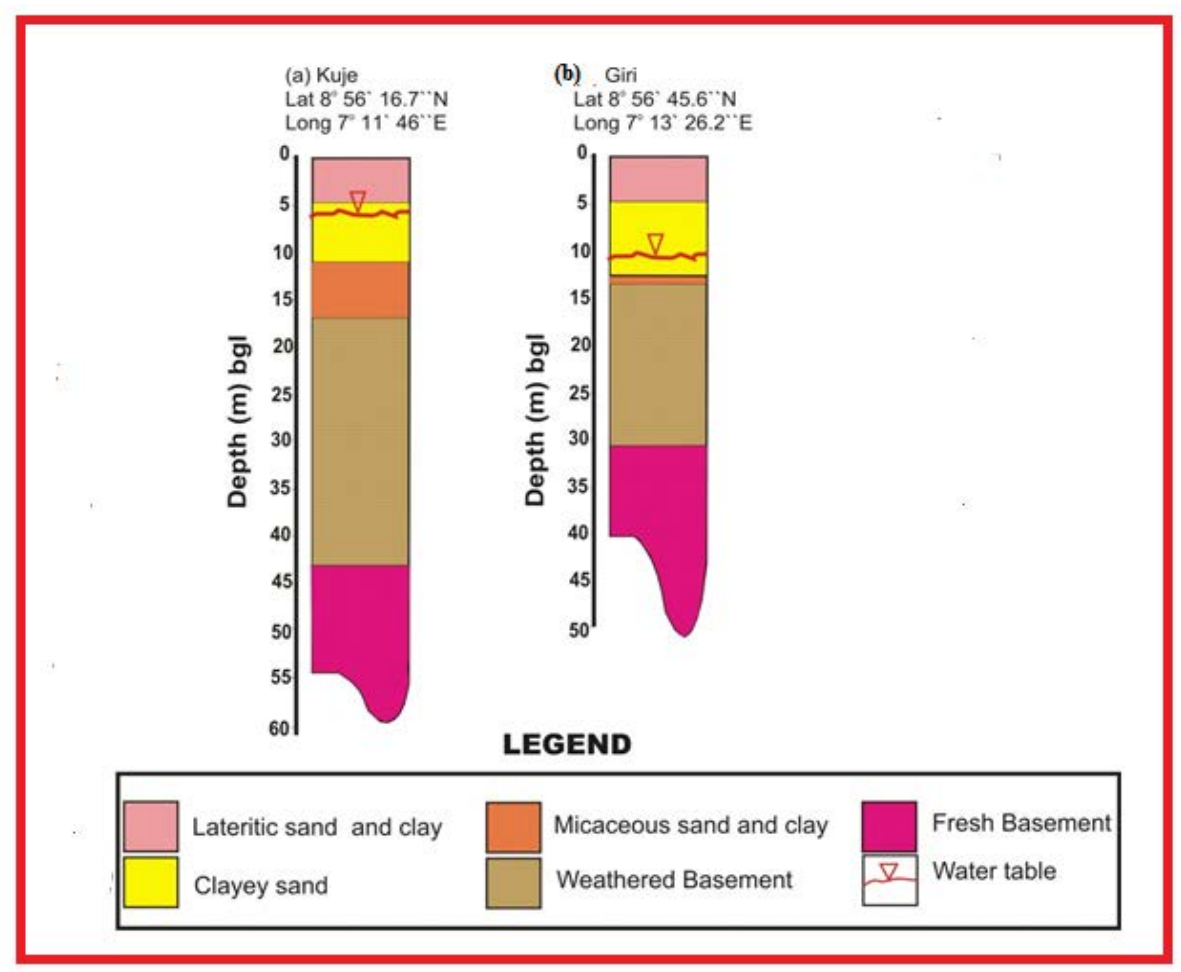

Figure 2: Presents the two borehole lithologies $(60 \mathrm{~m}$ and $50 \mathrm{~m})$ in the study area. 


\section{ACTIVITY CONCENTRATION OF ${ }^{226}$ RA IN WATER SAMPLES}

Table 1 illustrates the activity concentration and Life Average Daily Dose of ${ }^{226} \mathrm{Ra}$ in groundwater in the study area and compares it to other work published elsewhere [10]. The activity concentrations of ${ }^{226} \mathrm{R}$ in groundwater supplies for drinking and domestic purposes ranges from $443 \mu \mathrm{Bq} \mathrm{L} \mathrm{L}^{-\mathrm{q}}$ to $849 \mu \mathrm{Bq} \mathrm{L} \mathrm{L}^{-1}$, with the highest value of $849 \mu \mathrm{Bq} \mathrm{L}^{-1}$ found at Kuje borehole and lowest value of $443 \mu \mathrm{Bq} \mathrm{L} \mathrm{L}^{-q}$ at Giri borehole. It was noted that the activity concentrations of ${ }^{226} \mathrm{Ra}$ in this present work at Kuje and Giri were distinctly lower than the international reference level according to Omeje et al. [11] by a factor of 2.7. The highest value of $849 \mu \mathrm{Bq} \mathrm{L}^{-\mathrm{L}}$ was recorded at Kuje and the lowest value of $400 \mu \mathrm{Bq} \mathrm{L}{ }^{-\mathrm{L}}$ was recorded at Giri. The values of the activity concentrations from the two boreholes are lower than those obtained from the public water supply and the hand-dug well, respectively. At the same time, the activity concentration of ${ }^{226} \mathrm{Ra}$ found in the hand-dug well is higher than the values obtained from the two boreholes as presented in Table 1. This higher activity level may be attributed to granitic materials intruding near the surface of the overburden where the aquifer is recharged through the weathered mantle. Considering the depth of the boreholes drilled in Fig. 2, an increase in ${ }^{226} \mathrm{Ra}$ may be due to an increase in depth below ground level which might have woken the granitic materials from the deep subsurface and dissolved in the aquifer-bearing rock in the aqueous phase. The hand-dug well reported the highest value in all the samples. Comparing the hand-dug well with the public water supply, it is still higher. Comparing the two boreholes with the hand-dug well, the values obtained for the boreholes are far lower than the well by factors of 2.9 and 5.4 respectively. Significantly, it may be that radon escapes faster in a well of a lower depth which may contribute to a higher value of ${ }^{226} \mathrm{Ra}$ at a shallower depth. In all these results, there are significant variations in depths, activities and soil type which affect the non-uniform radium activity in the study area.

Table 1: Results of activity concentrations and the lifetime average daily dose (LADD) of ${ }^{226} \mathrm{Ra}$ in water samples from the study area, and comparison with various other countries and international standards.

\begin{tabular}{|l|l|l|l|}
\hline Location & $\begin{array}{l}\text { Activity concentration } \\
{ }^{22} R a\left(\mu B \mathrm{~L} \mathrm{~L}^{-1}\right)\end{array}$ & $\begin{array}{l}\text { LADD } \\
\left(\mu g \mathrm{~kg}^{-1} \mathrm{day}^{-1}\right)\end{array}$ & Reference \\
\hline Kuje & 849 & $2 \times 10^{-3}$ & Present study \\
\hline Giri & 443 & $1 \times 10^{-3}$ & Present study \\
\hline Water Board & 1824 & $4 \times 10^{-3}$ & Present study \\
\hline Hand-dug well & 2430 & $5 \times 10^{-3}$ & Present study \\
\hline $\begin{array}{l}\text { USE USEPA, Council } \\
\text { Directive 98/83/EY/ }\end{array}$ & 19,000 & - & $\begin{array}{l}\text { USE (Zoorob et al. } \\
[14])\end{array}$ \\
\hline RFD (reference dose) & - & $6 \times 10^{-1}$ & Ye-shin et al. [15] \\
\hline
\end{tabular}




\section{CHEMICAL TOXICITY RISK OF ${ }^{226}$ RA IN \\ GROUNDWATER FROM THE STUDY AREA}

The chemical toxicity was recorded to determine the effect of the carcinogenic risks associated with chemical toxicity of ${ }^{226} \mathrm{Ra}$ in the water sample selected for this study. The chemical toxicity risk was evaluated using the lifetime average daily dose of ${ }^{226} \mathrm{Ra}$ through drinking water intake, which was compared with the reference dose (RfD) of $0.6 \mu \mathrm{g}$ $\mathrm{kg}^{-1}$ day $^{-1}$ [11] used as a standard criteria for ${ }^{226} \mathrm{Ra}$ in several foreign organizations and thereby used to obtain the lifetime average daily dose (LADD). Eqn (1) represents the ingestion LADD of drinking water which is given as:

$$
\frac{E P C \times I R \times E F \times E D}{A T \times B W},
$$

where, $L A D D$ is lifetime average daily dose $\left(\mu \mathrm{g} \mathrm{kg}^{-1}\right.$ day $\left.^{-1}\right), E P C$ is the exposure point concentration $\left(\mu \mathrm{g} \mathrm{L}^{-1}\right), I R$ is the water ingestion rate $\left(\mathrm{L} \mathrm{day}^{-1}\right), E F$ is the exposure frequency (days year ${ }^{-1}$ ), ED is the total exposure duration (years), AT is the average time (days), and $B W$ is the body weight $(\mathrm{kg})$. Using $I R=2 \mathrm{~L} \mathrm{day}^{-1}, E F=350$ days, $E D=45.5 \mathrm{y}, A T=16,607.5$ (obtained from $45.5 \times 365$ ) and $B W=70 \mathrm{~kg}$ (for a standard man). The chemical toxicity risk for ${ }^{226} \mathrm{Ra}$ over a lifetime consumption was estimated and presented in Table 1. In Table 1, the exposure dose ranged from $1 \times 10^{-3}$ to $5 \times 10^{-3} \mu \mathrm{g} \mathrm{kg}^{-1}$ day . The $L A D D$ s values were observed to be higher in the Kuje borehole compared to Giri borehole. It can be observed that the hand-dug water sample is higher than both borehole samples in Table 1. This higher LADD in the hand-dug well may pose health risks to the inhabitants in the region. This could be as a result of toxic materials leaching from Gwarimpa Lake towards the eastern axis of the borehole.

\section{CONCLUSIONS}

Insignificantly, the presence of lower values of ${ }^{226} \mathrm{Ra}$ in the water samples and its associated LADD may not impose health complications to the dwellers that depend on groundwater but recommends adequate treatment measures before consumption to decrease the risk if the means is possible. It is clear that the maximum permissible levels of ${ }^{236} \mathrm{Ra}$ established by WHO in 2006, UNSEAR in 2000 and national legislations are generally based on toxicological studies on animals in the laboratory. The long-term human exposure to harmful elements in water should be our concern, irrespective of how little the concentration could be found in water-based drinking. This research calls for a further impact assessment of other toxic metals and other radioisotopes in water samples to know the long-term effects of these elements to human health in the study area. The overall quality of the water supply in the study area was found to be satisfactory in terms of potential risks of ${ }^{236} \mathrm{Ra}$ which was within the range of permissible limit.

\section{ACKNOWLEDGEMENTS}

The authors would like to thank the Universiti Tun Hussein Onn Malaysia, 86400 Parit Raja for providing equipment for water analysis and the Covenant University Ota for financial support. The authors wish to thank SYB Sinyoung Borehole Limited for providing the Rig and Compressor used in drilling the boreholes and Maxico Hydrosolution consult for providing the Campus Ohmega tetrameter. 


\section{REFERENCES}

[1] Lucas, H. \& Markun F., The determination of ${ }^{226} \mathrm{Ra}$ and ${ }^{228} \mathrm{Ra}$ in water and solids by the least squares gamma spectrometric method. Journal of Environmental Radioactivity, 1992. DOI: 10.1016/0265-931x(92)90039-v.

[2] Lyengar, M.A., The natural distribution of radium. The environmental behavior of radium. IAEA, Technical Reports Series, 310(1), pp. 9-128, 1990.

[3] Kurttio, P., Komulainen, H., Leino, A., Salonen, L., Auvinen, A. \& Saha, H., Bone as a possible target of chemical toxicity of natural uranium in drinking water. Environ Health Perspect Environmental Health Perspectives, 2004. DOI: 10.1289/ehp.7475.

[4] Lyman, G.H., Lyman, C.G. \& Johnson, W., Association of leukemia with radium groundwater contamination. JAMA, 254(5), pp. 621-626, 1985.

[5] Finkelstein, M.M., Radium in drinking water and the risk of death from bone cancer among Ontario youths. CMAJ, 151(5), pp. 565-571, 1994.

[6] Finkelstein, M.M. \& Kreiger, N., Radium in drinking water and risk of bone cancer in Ontario youths: A second study and combined analysis. Occup Environ Med, 53(5), pp. 305-311, 1996.

[7] Oyawoye, M.O., The basement complex of Nigeria. African Geology, eds T.F.J. Dessauvagie \& A.J. Whiteman, Ibadan, pp. 66-102, 1972.

[8] Black, R.R., et al., Evidence for late Precambrian plate tectonics in West Africa. Nature, 278, pp. 223-227, 1979.

[9] Rahaman, M.A., Recent advances in the study of the basement complex of Nigeria. Precambrian Geology of Nigeria, Geol. Survey of Nigeria Publication, pp. 11-43, 1988.

[10] Dai, S., et al., Revisiting the late Permian coal from the Huayingshan, Sichuan, southwestern China: Enrichment and occurrence modes of minerals and trace elements. International Journal of Coal Geology, 122(0), pp. 110-128, 2014.

[11] Omeje, M., Wagiran, H., Zaidi, E., Joel, E.S., Tenebe, I.T., Oha, I.A. \& Onwuka, O.S., Radiotoxicity risks of radium-226 $\left.{ }^{226} \mathrm{Ra}\right)$ on groundwater-based drinking at Dawaki, Kuje, Giri and Sabon-Lugbe area of Abuja, North Central Nigeria. Environ Earth Sci, 75, p. 1084, 2016.

[12] Prange, A. \& Profrock. D., Application of CE-ICP-MS and CE-ESI-MS in metalloproteomics: Challenges, developments, and limitations. Anal. Bioanal. Chem., 383(3), pp. 372-389, 2005.

[13] Council Directive 98/83/EY/ (1996): The quality of water intended for human consumption. Official Journal of the European Communities, L 330, 05/12/1998 s., pp. 0032-0054.

[14] Zoorob, G.K., McKiernan, J.W. \& Caruso J.A., ICP-MS for elemental speciation studies. Mikrochim. Acta., 128(3-4), pp. 145-168, 1998.

[15] Ye-shin, K., Hoa-sung, P., Jin-yong, K., Sun-ku, P., Byong-wook, C., Ig-hwan, S. \& Dong Chun, S., Health risk assessment for uranium in Korean groundwater. J. Environ. Radioct., pp. 77-85, 2004. 